\title{
The ultrasonic changes in maturing placenta in pregnancy complicated with hypertension and its correlation with neonatal outcome
}

\author{
Amit Dutta ${ }^{1}$, Kripasindhu Chatterjee' ${ }^{2}$ Sukanta Sen ${ }^{3 *}$, Swapan Kumar Ray $^{2}$, \\ Pradyut Kumar Mandal ${ }^{2}$, Sima Mukhopadhyay ${ }^{1}$
}

\begin{abstract}
${ }^{1}$ Department of Obstetrics and Gynaecology, ${ }^{2}$ Department of Pediatrics, ${ }^{3}$ Department of Pharmacology, ICARE Institute of Medical Sciences and Research, Banbishnupur, Purba Medinipur, Haldia, West Bengal, India
\end{abstract}

Received: 21 January 2017

Accepted: 28 February 2017

\author{
*Correspondence: \\ Dr. Sukanta Sen, \\ E-mail: drsukant@gmail.com
}

Copyright: () the author(s), publisher and licensee Medip Academy. This is an open-access article distributed under the terms of the Creative Commons Attribution Non-Commercial License, which permits unrestricted non-commercial use, distribution, and reproduction in any medium, provided the original work is properly cited.

\begin{abstract}
Background: Hypertension is the most common medical problem encountered during pregnancy, complicating 2-3\% of pregnancies. Obstetric ultrasound provides a cornerstone to other modalities used for assessing hypertensive disorders of pregnancy. This study was designed to detect the placental changes in hypertensive disorders of pregnancy and correlation with neonatal outcome.

Methods: The study group comprised of 42 patients with pregnancy complicated with hypertension with period of gestation above 20 weeks and B.P. more than 140/90 $\mathrm{mm}$ of $\mathrm{Hg}$ measured on two occasions 6 hours or more apart. The control group consists of 42 normotensive patients matched with age and parity. One ultrasonic examination were performed between 28 weeks and 34 weeks and another after 34 weeks till term. Apart from routine parameters i.e. BPD, AC, FL, Amniotic fluid index, EBW and gestational age routine placental grading were performed according to the classification proposed by Grannum and associates. To evaluate perinatal outcome following measurement were studied - birth weight immediately after delivery, mode of delivery, perinatal morbidity and mortality, APGAR score, presence of fetal distress.

Results: In $97.62 \%$ cases (41 out of 42 ) of control group showed Grade-II changes as opposed to $57.14 \%$ of cases ( 24 out of 42 ) in study group before 34 weeks.

Conclusions: Accelerated maturation of placenta in pregnancy complicated with hypertension are more common in the hypertensive group.
\end{abstract}

Keywords: Hypertension, Neonatal outcome, Obstetric ultrasound, Placenta, Pregnancy

\section{INTRODUCTION}

Every mother waits for long nine months with tremendous anxiety and expectation to get a healthy full term baby. Today medical technology has come all the way to shoulder to assess the feotal status in utero and thus to curtle the burden of anxiety for the mother as well as her clinician with its newer developments, one of which is ultrasound. Hypertension is the most common medical problem encountered during pregnancy, complicating 2-3\% of pregnancies. Hypertension occurs in $8 \%$ of pregnancies and contributes to $18 \%$ of fetal and infant mortality rates and to about $40-50 \%$ of infant who are low birth weight. ${ }^{1}$ Hypertensive disorders during pregnancy are classified into 4 categories, as recommended by the National high blood pressure education program working group on high blood pressure in pregnancy. ${ }^{1}$

- Chronic hypertension

- Preeclampsia-eclampsia

- Preeclampsia superimposed on chronic hypertension 
- Gestational hypertension (transient hypertension of pregnancy or chronic hypertension identified in the latter half of pregnancy). ${ }^{1}$ This terminology is preferred over the older but widely used term "pregnancy-induced hypertension" (PIH) because it is more precise.

The demography and potential profile of a patient that may develop pre-eclampsia includes the following: ${ }^{1}$

- Occurs in 6 to $8 \%$ of pregnancies and is principally a disease of first pregnancy $(85 \%)$.

- Occurs in $25 \%$ of patients with chronic hypertension and or chronic renal disease.

- Women who have repetitive severe disease during pregnancy most likely have a genetic tendency of a recessive gene.

- Occurs in 14- $20 \%$ of multiple gestations and $30 \%$ of patients with major uterine anomalies.

In summary, obstetric ultrasound provides a cornerstone to other modalities used for assessing hypertensive disorders of pregnancy. Placental grading is an empirical classification introduced by Grannum and Hobbins. ${ }^{2}$

It is based on modification that appears in the chorionic plate, basal layer and the placental substance. Placental maturation and insufficiency is diagnosed by studying placental grading. This study was designed to detect the placental changes in hypertensive disorders of pregnancy and correlation with neonatal outcome.

The study was designed to analyze the accelerated placental grading in pregnancies complicated with hypertension and its correlation with immediate neonatal outcome. The study also analysed the incidence of fetal distress, birth asphyxia, in relation to the placental grading.

\section{METHODS}

This study was conducted in the Department of Obstetrics \& Gynaecology, ICARE Institute of Medical Sciences \& Research, Haldia in the one year period of time November 2014 to November 2015 after taking permission from institutional ethics committee. The study group comprised of 42 patients with pregnancy complicated with hypertension with period of gestation above 20 weeks and B.P. more than 140/90 mm of $\mathrm{Hg}$ measured on two occasions 6 hours or more apart.

The control group consists of 42 normotensive patients matched with age and parity. All patients were subjected to routine antenatal examination and ultrasonic examinations were performed at least twice using Aloka Echo Model LS-280 machine. One ultrasonic examination was performed between 28 weeks and 34 weeks and another after 34 weeks till term. Apart from routine parameters i.e. BPD, AC, FL, Amniotic fluid index, EBW and gestational age routine placental grading were performed according to the classification proposed by Grannum and associates. ${ }^{2}$ Other special laboratory investigations were carried out such as serum uric acid, blood urea, serum creatinine and fundoscopy examinations. To evaluate perinatal outcome following measurement were studied-birth weight immediately after delivery, mode of delivery, perinatal morbidity and mortality, APGAR score, presence of fetal distress.

\section{RESULTS}

In the study, 42 cases of pregnancy complicated with hypertension and 42 normotensive cases were selected. Patients of both groups matched with age and parity. In present study incident of placental grading is presented in this Graph I and Graph II. Placental grade III changes were demonstrated before 34 weeks in $38.09 \%$ of cases, (16 out of 42) whereas none of control group shows grade III placental maturity before 34 weeks.

Table 1a: Mode of delivery.

\begin{tabular}{|ll|}
\hline Control & \multicolumn{2}{l|}{42} \\
\hline Operative intervention & $6(14.28 \%)$ \\
\hline$\bullet \quad$ LSCS & $\bullet 1(16.6 \%)$ \\
- Outlet forceps & $\bullet \quad 5(83.34 \%)$ \\
\hline No intervention & $36(85.72 \%)$ \\
\hline
\end{tabular}

Table 1b: Mode of delivery.

\begin{tabular}{|ll|}
\hline Study group & 42 \\
\hline Induced & $\mathbf{1 7}(\mathbf{4 0 . 4 7 \%})$ \\
\hline OP intervention & $15(95.34 \%)$ \\
$\bullet \quad$ LSCS & $08(53.33 \%)$ \\
- Outlet forceps & $07(46.67 \%)$ \\
NO intervention & $02(4.76 \%)$ \\
\hline Spontaneous & $\mathbf{1 5}(\mathbf{3 5 . 7 1 \%})$ \\
\hline OP intervention & $11(73.33 \%)$ \\
$\bullet \quad$ LSCS & $01(9.09 \%)$ \\
$\bullet \quad$ Outlet forceps & $10(90.90 \%)$ \\
NO intervention & $04(26.66 \%)$ \\
\hline LSCS & $\mathbf{1 0}(\mathbf{2 3 . 8 \%})$ \\
\hline
\end{tabular}

In $97.62 \%$ cases (41 out of 42) of control group showed Grade-II changes as opposed to $57.14 \%$ of cases (24 out of 42) in study group before 34 weeks. We had one case $(4.34 \%)$ showing Grade-I changes at 30 weeks, where extensive calcification was seen, which had to be terminated because of uncontrolled blood pressure and intrauterine death. In the study group $16.67 \%$ (7 out of 42 patients) had Grade-III placenta after 34 weeks and $80.95 \%$ (34 out of 42 patients) had Grade III placenta after 34 weeks.

Thus, the premature finding of Grade-III changes in hypertensive group may be due to placental dysfunction and senescence rather than just normal maturity of progress. Thus, variety of Grade-III changes in 
uncomplicated pregnancy supports this study. Study group was divided into mild PIH where BP below $160 / 110 \mathrm{~mm}$ of $\mathrm{Hg}$, and severe PIH above 160/110 mm of $\mathrm{Hg}$.

Table 2: Feto-placental ratio in case and control group.

\begin{tabular}{|lllll|}
\hline Group & $\begin{array}{l}\text { No of } \\
\text { cases }\end{array}$ & $\begin{array}{l}\text { Birth } \\
\text { weight } \\
\text { (gms) }\end{array}$ & $\begin{array}{l}\text { Placental } \\
\text { weight } \\
\text { (gms) }\end{array}$ & $\begin{array}{l}\text { F.P. } \\
\text { Ratio }\end{array}$ \\
\hline Control & 42 & 2720 & 461.2 & 5.9 \\
\hline $\begin{array}{l}\text { B.P } \\
<160 / 110\end{array}$ & 28 & 2600 & 473.9 & 5.4 \\
\hline $\begin{array}{l}\text { B.P> } \\
160 / 110\end{array}$ & 14 & 2060 & 390.0 & 5.2 \\
\hline
\end{tabular}

As it is seen in the above table feto-placental, ratio in study group showed a decrease in feto-placental ratio as compared to the control group. The ratio is more decreased in severe hypertensive group (5.28) as compared to control group (5.9), whereas normal fetoplacental ratio varies from 6.35 to 7.9 .

Fetal mortality and morbidity was high in the study group as compared to the control group (Table 3 and 4).

\section{DISCUSSION}

Ultrasonic study has shown that the strong echoes detected ultrasonically during antenatal scanning of the placental correspond to deposits of fibrin and calcium. Caroll et al found $22.7 \%$ incidence of accelerated placental maturation out of 56 cases studied; in the present study, incidence of accelerated placental maturation was seen in $38.09 \%$ of cases before 34 weeks. $^{3}$

According to Fox, in uncomplicated pregnancy placental infarction play little role in perinatal mortality and morbidity. ${ }^{4,5}$ But extensive infarction as found in hypertensive in hypertensive complication of pregnancy is associated with high incidence of fetal hypoxia. This correlated with the present study where there was 18 out of 28 cases $(64.28 \%)$ showed APGAR Score $<7$ in the study group, where Grade-III changes are seen before 34 weeks.

Krause could not find any significant lesion in was seen placenta which were specified to hypertensive disorder. ${ }^{6}$ And they also stated that there was no correlation with fetal outcome and placental changes. It was Fox studied lesions that obstruct or alter blood flow through the placenta. ${ }^{5}$ Fox also stated retroperitoneal hematoma is found in $4-5 \%$ of all placentas, and their incidence is therefore much higher than that of clinically detectable abruption placenta. ${ }^{5}$

Small hematomas have no clinical significance. Large hematoma is associated with high incidence of fetal hypoxia and death; largely because a very considerable proportion of the villi are actually separated from the maternal utero-placental circulation

Despite its reserve capacity of the placental cannot compensate for an abrupt loss of 40-50 \% of its functioning villi. In our study we had no cases where there were no retroplacental hematomas or abruptio. ${ }^{6}$ Very little is known about the factors that control placental maturation and placental growth, not necessarily the two process go hand in hand. ${ }^{7}$

Table 3: Fetal outcome in study group.

\begin{tabular}{|c|c|c|c|c|c|c|c|}
\hline \multirow{2}{*}{ Fetal outcome } & \multicolumn{2}{|l|}{ Grade I } & \multicolumn{2}{|l|}{ Grade II } & \multicolumn{2}{|l|}{ Grade III } & \multirow{2}{*}{$\begin{array}{l}\text { Total } \\
\%\end{array}$} \\
\hline & < 34 Weeks & >34 Weeks & <34 Weeks & >34 Weeks & <34 Weeks & >34 Weeks & \\
\hline Fetal distress & - & - & - & - & $10(23.81 \%)$ & $04(9.52 \%)$ & 14 \\
\hline APGAR <7 & - & - & - & - & $18(42.8 \%)$ & $10(23.8 \%)$ & 28 \\
\hline FSB & $01(2.38 \%)$ & - & - & - & & - & 01 \\
\hline IUD & $02(4.76 \%)$ & - & - & - & & - & 02 \\
\hline Neonatal death & - & - & - & - & $03(7.14 \%)$ & - & 03 \\
\hline IUGR & - & - & - & - & $03(7.14 \%)$ & - & 03 \\
\hline
\end{tabular}

Table 4: Fetal Outcome in Control Group.

\begin{tabular}{|c|c|c|c|c|c|c|c|}
\hline \multirow{2}{*}{ Fetal outcome } & \multicolumn{2}{|l|}{ Grade I } & \multicolumn{2}{|l|}{ Grade II } & \multicolumn{2}{|l|}{ Grade III } & \multirow{2}{*}{$\begin{array}{l}\text { Total } \\
\%\end{array}$} \\
\hline & <34 Weeks & >34 Weeks & <34 Weeks & >34 Weeks & <34 Weeks & >34 Weeks & \\
\hline Fetal distress & - & - & - & $1(2.38 \%)$ & - & $3(7.14 \%)$ & 4 \\
\hline APGAR <7 & - & - & - & $3(7.14 \%)$ & - & $1(2.38 \%)$ & 4 \\
\hline FSB & - & - & - & - & - & - & - \\
\hline IUD & - & - & - & - & - & - & - \\
\hline IUGR & - & - & - & - & - & $1(2.38 \%)$ & 1 \\
\hline Neonatal death & - & - & - & - & - & - & - \\
\hline
\end{tabular}


Placental infarction of more than $5 \%$ surface area was considered pathological as it was significantly more frequent in cases of toxemia as stated by Mirchandani et al, in their study. ${ }^{8}$ They studied 100 patients and stated that extensive infarction was found in the hypertensive group, is associated with incidence of fetal hypoxia. This correlates with present study where it was seen that infarction, calcification, necrosis was seen to the extent of $95.5 \%$ in the study group where, there was Grade-III changes before 34 weeks.

Grannum et al could demonstrate the changes by ultrasonography and graded placental changes according in Grade-0, Grade-I, Grade-II, and Grade-III. ${ }^{2} \mathrm{He}$ also states that there is accelerated grading of placenta in toxemia of pregnancy. But the exact percentage in their study is not mentioned.

Quinlan and Cruz et al started that out of 41 patients studied, $3(7 \%)$ had placental abruption. ${ }^{9,10}$ But in the present study there was no cases of abruption in the study group nor in the control group. On the contrary, there were 3 cases $(7.14 \%)$ had sub-chorionic haemorrhage on ultrasonography, and all of these neonates developed fetal distress.

Hill et al studied 128 high risk and 60 healthy gravidas between 28 weeks and term, comparing placental grade, risk factor and gestational age. ${ }^{11,12}$ They found a strong positive correlation among accelerated placental maturation with hypertension and intrauterine growth retardation. But exact percentage was not indicated in the study. In this present study, $45 \%$ of cases showed low APGAR score and these cases also showed Grade-III placental changes before 34 weeks.

Damania et al stated that pathological changes increased as the hypertension increased as the hypertension increases the fetoplacental ratio decreases with increased toxemia. ${ }^{13}$ In their study they got value to the extent of 5.71 , in the severe hypertensive group as compared to mild to hypertensive group 5.97. In the present study the fetoplacental ratio was 5.2 in the severe hypertensive group and 5.4 in mild hypertensive group.

Chin-chiu, Marshall D, et al studied 157 patients of which 95 were pre-eclamptic. ${ }^{14}$ In their study they had 6 neonatal deaths of which 4 were due to complications of prematurity. This results correlates with the present study, where there was 3 neonatal deaths and mainly due to complication of prematurity, there was no neonatal death in control group.

Kazz et al stated that the fetoplacental unit in hypertensive disorders of pregnancy is under jeopardy when blood pressure increases. ${ }^{15}$ They studied 100 non diabetic hypertensive and 100 control gravidas matched for gestational age between 28 weeks and 43 weeks. All had sonographic examination and routine antenatal follow-up, there was major accelerating effect on placental grade. They also stated that this maturation is an unreliable clinical predictor of feotal lung maturity in preeclampsia. But the draw back in the study was that they did not mention the exact value of placental maturation. He stated that there is a definite accelerated grading seen in hypertensive cases, which may be due to low oxygen tension and chorionic hypoxia sate that the placenta experiences.

Aston and associate evaluated 1082 women sonographically after 20 weeks of gestation. ${ }^{16} 1033$ Grade-III placenta (12\%). They stated there was no correlation with Hyaline Membrane Disease and Grade III placenta. In the present study ,16 out of $42(38.09 \%)$ showed Grade III placenta before 34 weeks , as compared there was no grade III changes before 34 weeks in the control group.

\section{CONCLUSION}

To summaries, the finding of Grade -III changes in placenta in pregnancies complicated with hypertension may be clinically useful in two ways:

- Grade III changes in the complicated study group and the old concept of post maturity are really, certainly not post mature but accelerated maturation and degenerative changes of the placenta. As regard histopathology evidence suggests that the placenta which in the past was thought to be insufficient is rarely so. It is a vigorous, energetic resourceful organ which in most cases of placental insufficiency may at times show compensatory changes in response to an unfavorable maternal milieu (i.e hypertension). The term "placental Insufficiency" should be very cautiously used for in most cases, its use reflects attention away from the true cases (i.e. hypertension) and treated promptly, which may cause failure of fetal growth and neonatal complications. The technique holds the definite promise since it is noninvasive, rapid, safe evaluation of fetal status in pregnancies complicate with hypertension. Further, studies will be required to evaluate the significance of these findings in the complicated pregnancy.

- In addition unexpected Grade-III changes in pregnancies complicated with hypertension may predict the development of late pregnancy problems in that pregnancy, though present study did not face such problems (e. g abruptio).

- Accelerated maturation of placenta in pregnancy complicated with hypertension is more common in the hypertensive group.

- Finding of accelerated grading in hypertensive group will alert the Obstetrician so far as neonatal outcome is concerned.

\author{
Funding: No funding sources \\ Conflict of interest: None declared \\ Ethical approval: The study was approved by the \\ Institutional Ethics Committee
}




\section{REFERENCES}

1. National high blood pressure education program working group on high blood pressure in pregnancy. Report of the national high blood pressure education program working group on high blood pressure in pregnancy. Am J Obstet Gynecol. 2000;183(1):S122.

2. Grannum PA, Berkowitz RL, Hobbins JC. The ultrasonic changes in the maturing placenta and their relation to fetal pulmonic maturity. Am J Obstet Gynecol. 1979;133(8):915-22.

3. Carroll B. Ultrasonic features of preeclampsia. J Clin Ultrasound. 1980;8(6):483-8.

4. Fox H. The significance of placental infarction in perinatal morbidity and mortality. Biol Neonat. 1967;11(1):87-105.

5. Fox H. The morphological basis of placental insufficiency. J Obstet Gynaecol India. 1975;25:44150.

6. Krause FT. Gynaecologic Pathology. Mosby Co. 446;1967.

7. Nobis P, Das U. Placental morphology in hypertensive pregnancy. J Obstet Gynecol. 1991;41:166-9.

8. Mirchandani JJ, Mallik GB, Chitra S. Correlation of foetal outcome with some pathological changes of placenta. J Obstet Gynaecol India. 1979;29:1131-9.

9. Quinlan RW, Cruz AL, Buhi WC, Martin M. Changes in placental ultrasonic appearance. II. Pathologic significance of grade III placental changes. Am J Obstet Gynecol. 1982;144:471-3.
10. Quinlan RW, Cruz AL, Buhi WC, Martin M. Changes in placental ultrasonic appearance. I. Incidence of grade III changes in the placenta in correlation to fetal pulmonary maturity. Am J Obstet Gynecol. 1982;144:468-70.

11. Hill LM, Breckle R, Ragozzino MW, Wolfgram KR, O'Brien PC. Grade 3 placentation: incidence and neonatal outcome. Obstet Gynecol. 1983;61:728-32.

12. Hills D, Irwin GA, Tuck S, Baim R. Distribution of placental grade in high-risk gravidas. American Journal of Roentgenology. 1984;143:1011-3.

13. Damania KR, Salvi VS, Ratnaparki SK, Daftari SN.The placenta in hypertensive disorder in pregnancy. J Obst and Gynaecol India. 1989;39:2831.

14. Lin CC, Lindheimer MD, River P, Moawad AH. Fetal outcome in hypertensive disorders of pregnancy. Am J Obstet Gynecol. 1982;142(3):25560.

15. GM Kazzi, Gross TL, Sokol R J, Kazzi N J. Detection of Intrauterine Growth Retardation: A New Use for Sonographic Placental Grading. Am J Obstet Gynecol March 1983;145(6):733-7.

16. Ashton SS, Russo MP, Simon NV, Shearer DM. Relationship between grade III placentas and biparietal diameter determinations. J Ultrasound Med. 1983;2:127-9.

Cite this article as: Dutta A, Chatterjee K, Sen S, Ray SK, Mandal PK, Mukhopadhyay S. The ultrasonic changes in maturing placenta in pregnancy complicated with hypertension and its correlation with neonatal outcome. Int J Reprod Contracept Obstet Gynecol 2017;6:1435-9. 